Having just returned from Florida and the Bahamas on a three week rugby football tour I found on my desk an invitation, or perhaps rather an instruction, from Peter Sperryn to present to you this morning a short paper on the Private Physiotherapist in Sports Medicine.

I mention the tour deliberately to make the point that it is only being a physiotherapist in private practice that allows me the time and money to indulge in such exotic trips at least once a year.

We have heard from Dr. Ian Adams of the problems of treating the injured athlete through the over worked and creaking National Health Service Casualty Departments. I believe that of the nine experimental sports injuries clinics set up some time ago four survive, the other five, victims of manpower and financial shortages. It is because of this and the unsatisfactory service that the injured sportsmen frequently receives through the N.H.S. that the private practitioner finds that there is a part to play.

I think that almost without exception all my colleagues in private practice have, after qualification, served their time in the National Health Service, but because of frustrations, mainly financial, have felt obliged to break forth on their own. These people who

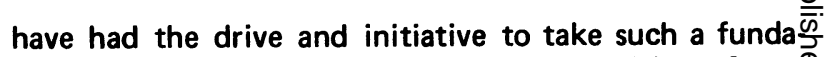
mental step have put themselves into a position of sup $\mathbb{D}$ plying services to a clientele who are paying their owry fees. When patients pay, they expect results. No results, no fees. Most of my colleagues in private practice have survived and $I$ think it fair therefore to assume that the are at least competant.

There are $\mathbf{2 4 0}$ members on the list of the Association of Chartered Physiotherapists in Sports Medicine and approximately half of these are in private practice. We therefore, have some 120 private practitioners scattered in all parts of the country who have the facilities and some experience and enthusiasm for the treatment of the injured competitor.

In almost every practice there is a special scale of fee? for the young athlete, and the enthusiastic practitiones makes little, if any money from the treatment of the amateur.

We recognize that the facilities we have are far from perfect and indeed are incomplete and I like to thi that we recognize our own limitations. Despite this, the private practitioners in sports medicine do at least offe the facilities they have and in proper collaboration witto doctors in the vicinity, both in general and in consulting practice, its something upon which to build.

Brit. J. Sports Med. - Vol. 11, No. 3, September 1977, p. 146

\title{
ICE IN THE TREATMENT OF SPORTS INJURIES
}

Yvonne WOOTTON-WHITLING, M.C.S.P.

Physiotherapy Dept., Hillingdon Hospital, Uxbridge, Middlesex

Cooling, when used as a mode of treatment, has a number of different physiological effects, and it is important to decide what effect is required in order to select the most suitable treatment modality.

It seems reasonable, therefore, to divide the injuries which might be met with in a sporting context into three groups which reflect the pathological state of the injured tissue.

The first group is made up of ACUTE injuries within the first few hours of their occurrence. These are charac- terised by cell damage and the rupture of blood vessels. and the primary aim of treatment is to reduce to minimum the formation of haematoma and oedema. $\$$ combination of compression, elevation, rest and prœ longed cooling of the limb with melting ice or cold wates is employed to achieve the maximum possible reductio通 of blood flow in the deep structures, and the locg slowing of metabolic processes.

When the acute stage has passed, these same injuries may be classified as SUBACUTE and now the judiciocts use of ice towels or packs can help the return to norma 